\title{
'Spear' through the right ventricle: pericardial tamponade caused by delayed pacemaker lead-related perforation of a normal thickness free wall which was managed percutaneously using the same lead
}

\author{
Apurva Vasavada, Mahesh Vinchurkar, Navin Agrawal, Pritesh Parekh
}

Department of Cardiology sciences, Care Hospital, Surat, Gujarat, India

Correspondence to Dr Navin Agrawal, drnavinagrawal@gmail.com

\section{DESCRIPTION}

Lead perforation is seen in around $0.1-1 \%{ }^{1}{ }^{2}$ of pacemaker implantation and is predominantly seen early in the course while occurrence after 1 month is much rarer.

A 58-year-old patient who had undergone implantation of a single-chambered VVI pacemaker using an active fixation lead more than 3 months ago for the presence of intermittent complete atrioventricular block presented with symptoms of progressively increasing dyspnoea and fatigue since the past 3-4 days. The patient was diagnosed to have pericardial tamponade (video 1 , figures 1 and 2) due to perforation of the normal thickness right ventricular (RV) free wall by the lead which

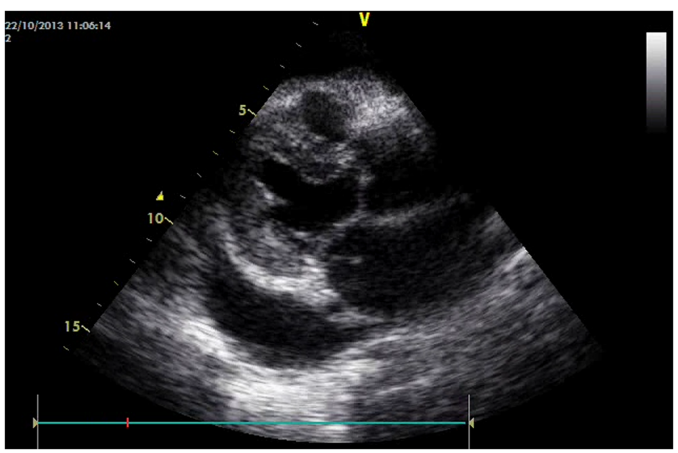

Video 1 Pericardial tamponade seen in the echo at presentation with large amount of pericardial fluid collected diffusely around in the pericardial space.

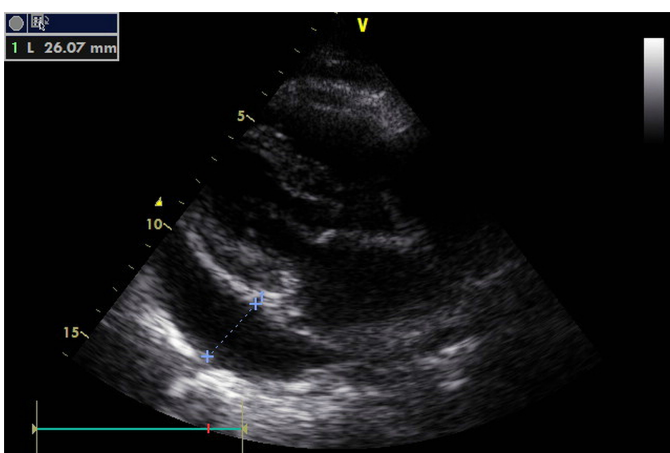

Figure 1 Parasternal long axis view showing the pericardial fluid collected around the heart. appeared to have passed through the free wall like a 'spear' through the endocardium into the pericardial space (videos 2 and 3, figure 3).

The patient underwent emergency pericardiocentesis during which around $350 \mathrm{~mL}$ of sanguineous pericardial fluid was drained (video 4, figure 4). The patient subsequently underwent repositioning of the same lead which was fixed to the septal position. Subsequent echocardiograms showed no further fluid recollection.

This case forms an interesting example of a delayed lead perforation leading to a lifethreatening acute pericardial tamponade in a patient undergoing active fixation lead implantation without most of the other conventional risk factors

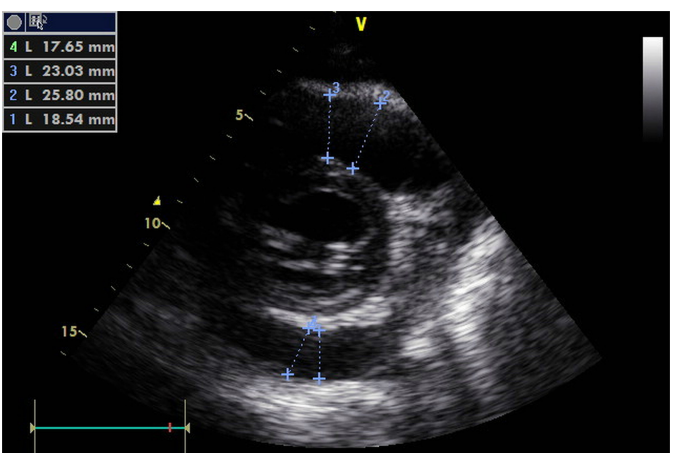

Figure 2 Another view in the short axis view showing large amount of pericardial fluid collected around the heart.

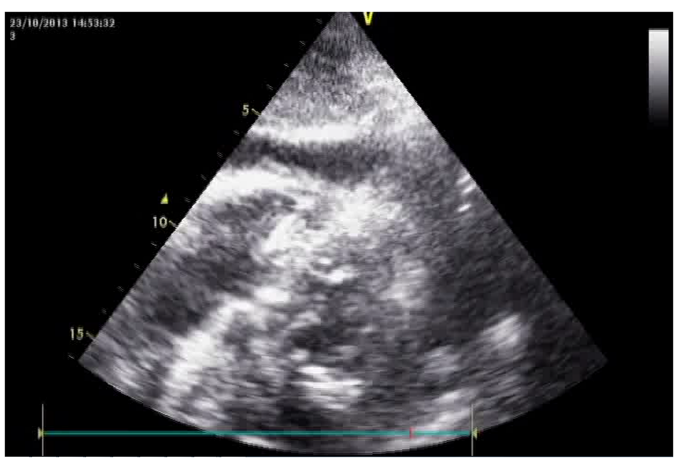

Video 2 Subcostal 4 chambered view showing the pacemaker lead having perforated through the RV fee wall of normal thickness. RV, right ventricular. 


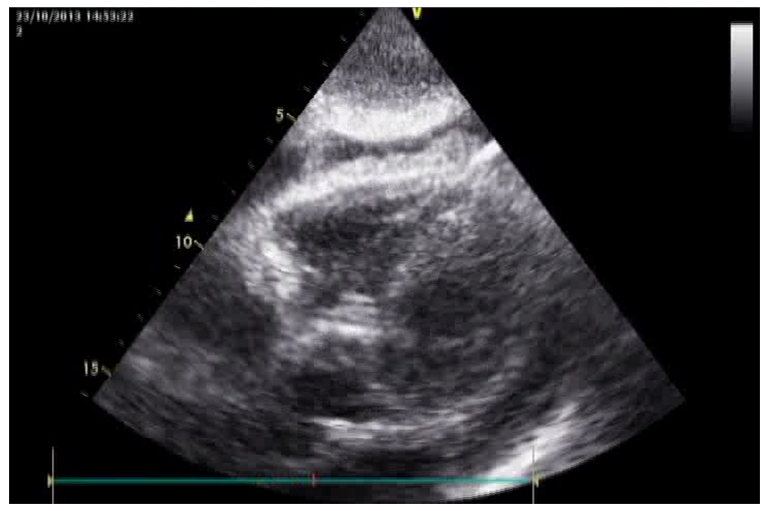

Video 3 Another subcostal view shows RV free wall perforation by the pacemaker lead. RV, right ventricular.

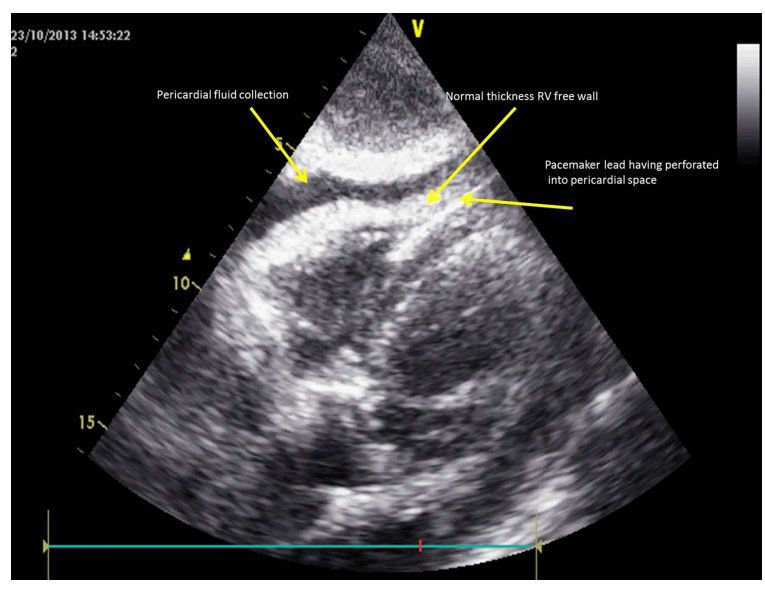

Figure 3 Subcostal four-chamber view showing perforation of the right ventricular free wall which was of normal thickness.

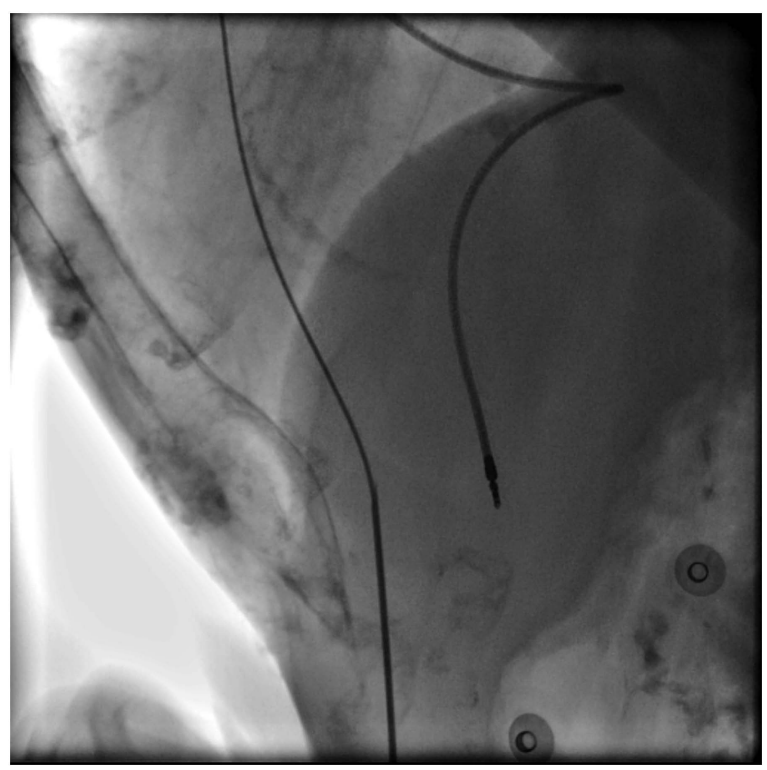

Video 4 Fluoroscopy done at the time of pericardiocentesis showing the RV pacemaker lead having perforated across the RV free wall into the translucent pericardial space. RV, right ventricular.

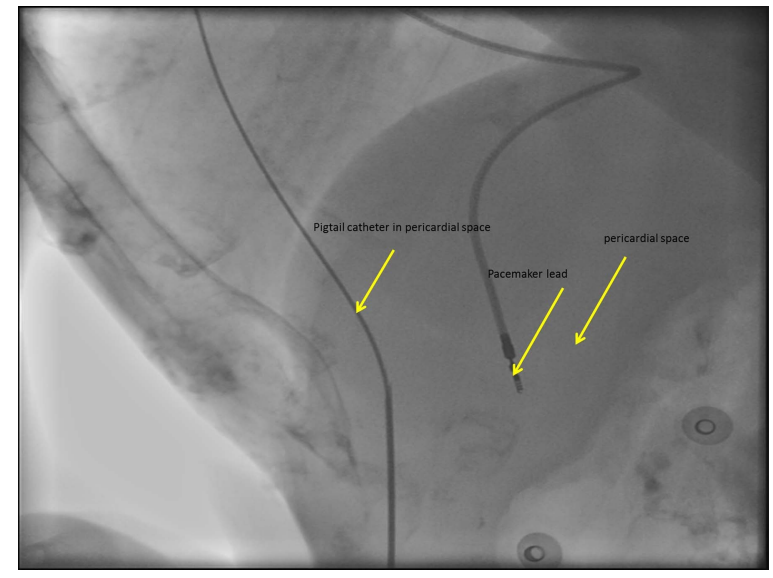

Figure 4 Fluoroscopic image showing the perforated lead having entered into the pericardial space.

such as the use of temporary leads, infarcted or thinned out RV free wall, steroid usage, low body mass index, female gender and concomitant anticoagulation therapy. ${ }^{3}$ This case is an interesting example where early diagnosis and conservative management using the same lead enabled to obtain a successful and lasting outcome in a life-threatening situation.

\section{Learning points}

- Pacemaker-related perforation, although uncommon, can happen in patients without obvious risk factors and can present with a life-threatening pericardial tamponade which can occur as late as after 3 months as happened in this case.

- Early recognition and high index of suspicion is the key to successful management which is often possible conservatively in appropriately selected cases and hence percutaneous therapy should be given a try before opting for a more invasive strategy.

- Active fixation leads should be used cautiously in elderly patients where perforation can present extremely late and even when other risk factors are not present. This calls for close vigilance in such cases despite the free wall thickness being normal.

- Septal position of implantation of the lead can be preferred in cases with other risk factors for perforation and in cases requiring active fixation leads to reduce the risk of free wall perforation.

Contributors All the authors have contributed in patient care and have helped in drafting and finalising the manuscript.

Competing interests None.

Patient consent Obtained.

Provenance and peer review Not commissioned; externally peer reviewed.

\section{REFERENCES}

1 Akyol A, Aydin A, Erdinler l, et al. Late perforation of the heart, pericardium, and diaphragm by an active-fixation ventricular lead. Pacing Clin Electrophysiol 2005;28:350-1.

2 Carlson MD, Freedman RA, Levine PA. Lead perforation: incidence in registries. PACE 2008;31:13-15.

3 Hermanides RS, Ottervanger JP, Elvan A, et al. Life threatening perforation of a defibrillation lead. Neth Heart J 2009;17:113-14. 
Copyright 2014 BMJ Publishing Group. All rights reserved. For permission to reuse any of this content visit http://group.bmj.com/group/rights-licensing/permissions.

BMJ Case Report Fellows may re-use this article for personal use and teaching without any further permission.

Become a Fellow of BMJ Case Reports today and you can:

- Submit as many cases as you like

- Enjoy fast sympathetic peer review and rapid publication of accepted articles

- Access all the published articles

- Re-use any of the published material for personal use and teaching without further permission

For information on Institutional Fellowships contact consortiasales@bmjgroup.com

Visit casereports.bmj.com for more articles like this and to become a Fellow 